\title{
Comparing opinion on needs of laboring women among mothers \& midwives working in labour room at a University Medical College Hospital
}

\author{
Prof pravati Tripathy ${ }^{1}$,Dr (prof) Prasanna Baby ${ }^{2}$ \\ SUM Nursing college,SOA University,Bhubaneswar,India \\ Principal,Faculty of Nursing,Sri Ramachandra University, Chennai,India
}

\begin{abstract}
Pregnancy and labour impose lots of physical, physiological and emotional strain on mother's life. It becomes difficult to balance life in such transaction period. Family members, husband and relatives need to know her expectation and meet them to ensure safe deliver \& a healthy baby. Nurses being one of the front line health care provider should feel her helplessness and realise her need during labour and come forward to satisfy those. Through this study the needs of a labouring woman as verbalised by herself and realised by nursing personnel is inquired through a structured opineir. The study was conducted upon 20mothers at their $1^{\text {st }}$ stage of labour and 20 midwives working in labour room. The opinions of both the groups were recorded and differences were seen through percentage. $75 \%$ women required complete privacy, $40 \%$ need husband near to her, $80 \%$ liked to change position frequently, $80 \%-70 \%$ want calm and quite environment, $70 \%$ liked cool liquid, $50 \%$ like back massage, $35 \%$ like slow breathing $75 \%$ liked to express feeling to near one, $50 \%$ liked to relieve anxiety by diverting mind, $90 \%$ want to know the progress, $60 \%$ wants to get information from doctors, whereas $50 \%$ alteration in opinion found in case of staff of labour room. Age \& parity was not associated with support \& relieving anxiety.
\end{abstract}

Key words: Comforting in Labour, labour needs, labour support

\section{Introduction}

For most women and families, labour \& birth is a time of excitement and anticipation, along with uncertainty, anxiety and fear. Giving birth represents a major transition in a women's life, not only she is becoming a mother, she will also be growing and learning throughout the processes. Birth is a life-changing event and the care given to women during labour has the potential to affect them both physically and emotionally in the short and longer term.

Women and their families should always be treated with kindness, respect and dignity. The views, believes and values of the woman, her partner and her family in relation to her care and that of her baby should be sought and respected, all the time. The woman should be fully involved in planning her birth. Woman should have the opportunity to make informed decision about the care and any treatment needed.

\subsection{Background}

Supporting women at delivery is an essential part of public health care. It includes physical comforting such as touching, massaging, bathing, grooming, applying warmth or cold and emotional support such as continues companion, reassurance, encouragement, anticipatory guidance, information provision and nonmedical advice and advocacy like relaying the woman's behalf, labour support and care may also involve procedures and facilitation of communication between woman and staff to assist her in making informed choice(1-3].

Many clinical randomized trials have shown that women who were accompanied by partners and assigned midwife during labour received less epidural anesthesia, analgesia and had fewer epitomizes and had a greater sense of control during labour compared with women permitted accompaniment by partners but not assigned midwives[4-7].

Supporting women in labor has many advantages like having shorter labors, reduced need for oxytocin, anesthesia, analgesia, instrumental deliveries and a decreased by $50 \%$ of cesarean section [1-7]. Also anxiety, post-partum depression, post-partum bleeding fever, low apgar and prolonged infant hospitalization can be also decreased[3-8].

While studying parturients' need for continuous labour support it was found significant need of increasing education level and family income $\left(\chi^{2}=8.71, \mathrm{P}=0.033\right.$ and $\left.\chi^{2}=13.4, \mathrm{P}=0.034\right)$. A significantly higher $\left(\chi^{2}=16.77, \mathrm{P}=0.001\right)$ proportion of married women preferred having a companion than unmarried. Also a higher proportion of women delivered by cesarean section wanted to have companion in labour that either with spontaneous or instrumental deliveries. Parturient suggested five possible measures to improve delivery services 
like increasing numbers of health workers $(34.0 \%)$, providing adequate analgesia $(25 \%)$, allowing family member/partner (19.8\%), health educations (16.3\%) and others (4.7\%)[9].

Main factors identified as influencing satisfaction and dissatisfaction were, caregivers and client interaction, the characteristics of the setting, the involvement of clients in the care process, the nurses' perception of client characteristics, the outcome of labour for both mother and baby. Caregiver attitude as seen as the strongest factor in determining maternal satisfaction than the interpersonal relationship[10].

\subsection{Purpose}

Labour is an intense physical and emotional experience. Every woman hopes her birth experience to be fearless and positive as possible. Mother once entered into labour room finds herself lonely, anxious and fearful. Nobody probes what she wants and likes. The policy and procedure goes in it's own way, but mother's need and expectation left unattended and unconsidered. After experiencing and realizing the situation in labour room author thought to know their needs how to be explored and known to all in comparing with ideas of midwives working in labour room who are going to satisfy the needs of a mother.

\subsection{Objectives}

- To explore the needs of mothers admitted in labour room

- To find out the opinion of midwives on needs of a woman in labour.

- To compare the consistency, gaps and inconsistency among both the groups

\section{Methodology}

The research design was explorative descriptive survey which tried to explore the kind of needs a woman during labour expects. The study was conducted at a university medical college hospital, Bhubaneswar in 2013. The study population was the midwives working in labour room \& the mothers who were in early $1^{\text {st }}$ stage of labour without serious complications. 20 from each groups were selected conveniently.

A structured questionnaire was prepared based on needs of mother during $1^{\text {st }}$ stage of labour and subdivided into four sections; physical, physiological, emotional and communication/informational need. Both the groups were explained the purpose of the study \& told to express their views \& opinion honestly what they realize \& viewed as best. In certain items mothers were given the care as required $\&$ helped them to differentiate the effects like back massage, hot application, positioning etc. The researcher conducted one-to-one interview. The mothers who were not willing to answer were excluded.

\section{Result}

TABLE-1

\section{Subject Characteristics}

\begin{tabular}{|c|c|c|c|c|c|c|c|c|c|}
\hline & \multicolumn{4}{|c|}{ Mothers at labour } & \multicolumn{4}{|c|}{ Midwives } & \\
\hline & $\begin{array}{l}\mathrm{n}=20 \\
\text { (f) }\end{array}$ & $\%$ & Mean & SD & & $\begin{array}{c}\mathrm{n}=20 \\
\text { (f) }\end{array}$ & $\%$ & Mean & $\mathrm{SD}$ \\
\hline \multicolumn{5}{|l|}{ Age (year) } & Age (year) & & & \multirow{4}{*}{23.7} & \multirow{4}{*}{2.11} \\
\hline$\leq 20$ & 2 & 10 & \multirow{3}{*}{25.35} & \multirow{3}{*}{5.7} & $<20$ & 0 & 0 & & \\
\hline $20-30$ & 16 & 80 & & & $20-30$ & 20 & 100 & & \\
\hline$>30$ & 2 & 10 & & & $>30$ & 0 & 0 & & \\
\hline \multicolumn{3}{|l|}{ Education } & & & Education & & & & \\
\hline Primary & 4 & 20 & & & ANM & 6 & 30 & & \\
\hline $\begin{array}{l}\text { Higher } \\
\text { secondary }\end{array}$ & 5 & 25 & & & G.N.M & 10 & 50 & & \\
\hline $\begin{array}{l}\text { Under } \\
\text { Graduate }\end{array}$ & 5 & 25 & & & B.Sc (N) & 4 & 20 & & \\
\hline Graduate & 2 & 10 & & & M.Sc (N) & 0 & 0 & & \\
\hline Parity & & & & & $\operatorname{Exp}(y \mathbf{r})$ & & & \multirow{5}{*}{2.35} & \multirow{5}{*}{1.26} \\
\hline Primi & 14 & 70 & \multirow{4}{*}{1.4} & \multirow{4}{*}{0.3} & $<1$ & 5 & 25 & & \\
\hline Multi & 6 & 30 & & & $1-3$ & 12 & 60 & & \\
\hline & & & & & $3-5$ & 2 & 10 & & \\
\hline & & & & & $>5$ & 1 & 5 & & \\
\hline
\end{tabular}

Mean age of the mothers was 25.35 and $100 \%$ of midwives were in the age group of $20-30$ years. $50 \%$ of them were diploma holders in nursing. $70 \%$ of mothers were primi with mean 1.4. Most $(60 \%)$ of the midwives had1 to3 years of experience with mean experience of 2.35 . 
Table-2

Distribution of subjects as per physical need

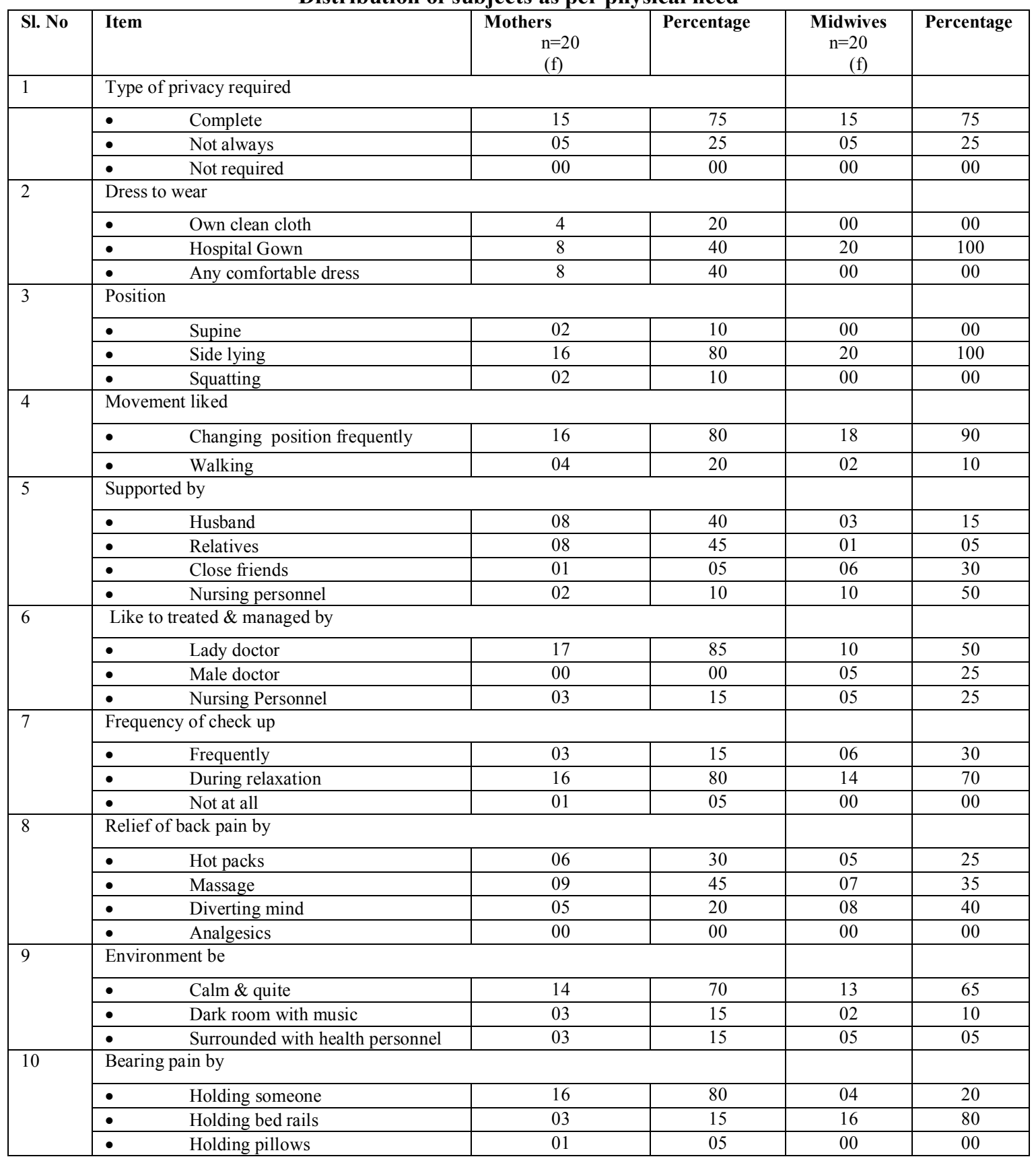

The mothers and midwives revealed differently regarding physical need during labour. In case of privacy both gave same opinion. But in changing dress some mothers revealed any comfortable dress or own clean clothes. $80 \%$ mothers liked side laying and where as $100 \%$ of midwives revealed so. $80 \%$ of mothers \& $90 \%$ of midwives revealed to change position frequently. $40 \%$ of mothers liked to be supported by husband $45 \%$ by relatives, whereas $50 \%$ midwives revealed to support by nursing personnel.

Table-3

Distribution of subjects according to Physiological Need

\begin{tabular}{|c|c|c|c|c|c|}
\hline SI. No & Item & $\begin{array}{c}\text { Mothers } \\
\mathrm{n}=20 \\
\text { (f) }\end{array}$ & Percentage & $\begin{array}{c}\text { Midwives } \\
\mathrm{n}=20 \\
\text { (f) }\end{array}$ & Percentage \\
\hline \multirow[t]{3}{*}{1} & \multicolumn{3}{|l|}{ Relieving dry mouth by } & & \\
\hline & Sips of water & 04 & 20 & 13 & 65 \\
\hline & $\begin{array}{ll}\bullet & \text { Cool liquid / ice chips }\end{array}$ & 15 & 75 & 07 & 35 \\
\hline
\end{tabular}


Comparing opinion on needs of laboring women among mothers \& midwives working in labour room

\begin{tabular}{|c|c|c|c|c|c|}
\hline & - $\quad$ Hot soup or drinks & 01 & 5 & 00 & 0 \\
\hline \multirow[t]{5}{*}{2} & \multicolumn{3}{|l|}{ Pain relieved by } & & \\
\hline & Deep breathing & 05 & 25 & 06 & 30 \\
\hline & Back massage & 10 & 50 & 10 & 50 \\
\hline & Music therapy & 00 & 00 & 04 & 20 \\
\hline & Holding nearby & 05 & 25 & 00 & 00 \\
\hline \multirow[t]{5}{*}{3} & \multicolumn{3}{|l|}{ Breath like } & & \\
\hline & Slow blowing (long and slow) & 0 & 0 & 06 & 30 \\
\hline & Hee breath (Slow \& deep) & 7 & 35 & 14 & 70 \\
\hline & Painting (quick \& shallow) & 1 & 5 & 00 & 00 \\
\hline & Strong blow (hard \& fast) & 12 & 60 & 00 & 00 \\
\hline \multirow[t]{4}{*}{4} & \multicolumn{3}{|l|}{ Sound like to be } & & \\
\hline & Low & 14 & 70 & 11 & 55 \\
\hline & • $\quad$ Murmuring & 03 & 15 & 01 & 05 \\
\hline & Slow music & 03 & 15 & 08 & 40 \\
\hline \multirow[t]{5}{*}{5} & \multicolumn{3}{|l|}{ During contraction pain managed by } & & \\
\hline & - $\quad$ Pressing on lower back & 7 & 35 & 03 & 15 \\
\hline & - $\quad$ Massaging on back & 9 & 45 & 14 & 70 \\
\hline & - $\quad$ Hot and cold pack on back & 04 & 20 & 03 & 15 \\
\hline & - $\quad$ Massaging abdomen & 00 & 00 & 00 & $0 \mathrm{O}$ \\
\hline
\end{tabular}

$75 \%$ vs. $35 \%$ mothers and staff viewed to have cool liquid and $65 \%$ staff suggested sips of water for dry mouth as they have practiced likewise. $50 \%$ of both cases gave opinion of back massage for relieving pain. $60 \%$ mothers go for strong blow breath, which is physiologically incorrect method. Both group suggested for low sound ( $45 \%$ vs. $70 \%$ )for reducing effect of contraction pain. Hot \& cold application is not still practiced in many hospitals for back pain.

Table-4

Distribution of subjects as per emotional need

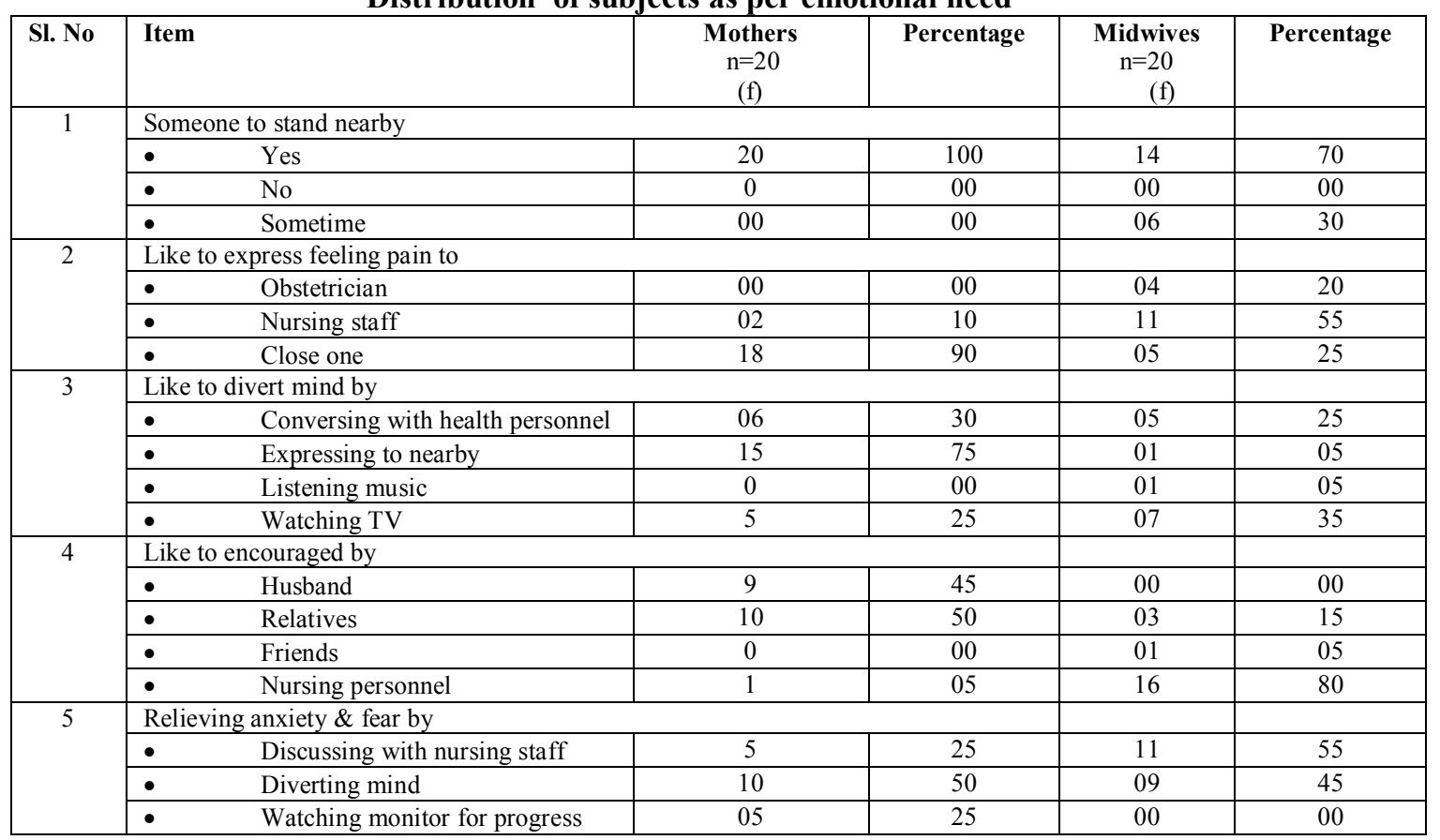

$100 \%$ mothers liked someone to stand nearby for relieving anxiousness. Also $70 \%$ of midwives gave same opinion. Most (90\%) of them liked to express feelings to close one. $75 \%$ revealed to divert mind by expressing to close one where as $60 \%$ staff told by conversing with them. $45 \%$ expressed husband $50 \%$ for relatives to be with them where as no midwives supported for husband and $15 \%$ for relatives and $90 \%$ for nursing personnel who can support them. 


\section{Tabel-5}

Distribution of subjects as per Communication Need

\begin{tabular}{|c|c|c|c|c|c|}
\hline Sl. No & Item & $\begin{array}{c}\text { Mothers (20) } \\
\mathrm{n}=20 \\
(\mathrm{f})\end{array}$ & Percentage & $\begin{array}{c}\text { Midwives (20) } \\
\mathrm{n}=20 \\
(\mathrm{f})\end{array}$ & Percentage \\
\hline \multirow[t]{4}{*}{1} & \multicolumn{3}{|l|}{ Required to know the progress } & & \\
\hline & Yes & 18 & 90 & 20 & 100 \\
\hline & Sometime & 02 & 10 & 00 & 00 \\
\hline & No & & & & \\
\hline \multirow[t]{4}{*}{2} & \multicolumn{3}{|l|}{ Information to get through } & & \\
\hline & Monitor & 00 & 00 & 09 & 45 \\
\hline & Doctor & 12 & 60 & 03 & 15 \\
\hline & Nurses & 08 & 40 & 08 & 40 \\
\hline \multirow[t]{4}{*}{3} & \multicolumn{3}{|l|}{ Communicating problems to } & & \\
\hline & Doctors & 13 & 65 & 09 & 45 \\
\hline & Nursing personnel & 07 & 35 & 11 & 55 \\
\hline & Close ones & 00 & 00 & 00 & 00 \\
\hline \multirow[t]{4}{*}{4} & \multicolumn{3}{|l|}{ Should clarify doubt } & & \\
\hline & Yes & 18 & 90 & 18 & 90 \\
\hline & Sometimes & 02 & 10 & 20 & 10 \\
\hline & No & 00 & 00 & 0 & 00 \\
\hline \multirow[t]{4}{*}{5} & \multicolumn{3}{|l|}{ Should know delivery steps } & & \\
\hline & Yes & 18 & 90 & 18 & 90 \\
\hline & Sometime & 02 & 10 & 02 & 10 \\
\hline & $\begin{array}{ll} & \text { No } \\
\end{array}$ & 00 & 00 & 00 & 00 \\
\hline
\end{tabular}

$90 \%$ mothers wished to know the progress, $60 \%$ to get the information through doctor and $40 \%$ through nurses. $45 \%$ mothers revealed to communicate their problems to doctor and $35 \%$ to nurses where as staff viewed it as $45 \%$ \& $55 \%$. Nurses need to pay more attention towards gaining confidence of mother. $90 \%$ of both the group wished mother should know delivery steps.

Tabel-6

Association of maternal age and parity with labour support.

\begin{tabular}{|l|l|l|l|}
\hline Characteristics & $\chi^{2}$ Value & P.Value & Significance \\
\hline Age & 2.297 & .8905 & NS \\
\hline Parity & 1.98 & .5766 & NS \\
\hline
\end{tabular}

The calculated chi square value for Age \& Parity is less than tabulated value. Hence, both are not significantly associated with labour support.

\section{Discussion}

The study revealed in certain aspects, the opinion of both the midwives and mothers are same like in items privacy, position, movements, relief of back pain, clarifying doubts \& interest in knowing delivery steps; but in other item like dress to wear, supported by, bearing pain by, relief from dry mouth, breathing type, pain management, expressing feelings to, diverting mind, encouraged by, the opinion differed much. Mothers liked to be supported by their husband and relatives where as staff feels nursing personnel can support them emotionally. The midwives should inquire the needs of a mother during labour and support them accordingly. They must be encouraged and communicated properly, so that needs can be met for better labour outcomes.

\section{Conclusion}

Emotional, tangible and informational supports are positively related to mothers' mental and physical health around the time of childbirth [11].Many environmental element influence a women's care during labour and birth. These include staffing pattern, attitude of staff, interpersonal relationship and expectations of those receiving care. Healthcare providers play a profound role at the time of birth facilitating attachment between mothers and newborns, as well as family closeness. We should aim to understand the needs and care a woman during labour and birth so as to ensure a positive experience for the woman and her family, while maintaining their health, preventing complications and responding to emergencies.

\section{Acknowledgement}

I thanks to HOD, Department of OBS \&G, In-charge, labour room, all the midwives \& mothers for their cooperation in completing the study. 


\section{References}

[1]. Klaus MH, Kennell JH. The doula: an essential ingredient of childbirth rediscovered. Act a prediat 1997; 86:1034-6

[2]. Kathryn D.S, Gale B, Marshall K. A comparison of intermittent and continuous support during labour: a meta analysis. Amr J obstet Gynaecol 1999; 180:1054-9

[3]. Penny P, Simkin; MA. Non pharmacological relief of pain during labour: systematic review of five methods. Amr J Obstet Gynecol 2002; 186(supp):131-59

[4]. Cogan R, Spinnato J. Social support during premature labour: effect on labour and the newborn, J Psychosom obstet Gynaecol 1988(8):209-16

[5]. Hudnett ED, Osborn RW. A randomized trial of the effect of monitrice support during labour: mother's views two to four weeks postpartum, Birth 1989;16:177-83

[6]. Hemminki E, Virta AL, Koponen P, Malin M, Kojo Austin H, Tirumala R. A trial on continuous human support during labour: feasibility, interventions and mothers' satisfaction. J psychosom obstet gynecol 1990;11:239-50

[7]. Breat G, Mlika-cabane N, Kuminski M, Alexander S, Herrozo Nalda, Mandrussato P, Evaluation of different policies for the management of labour-Early human dev 1992;29(1-3):309-12

[8]. Ellen DH. Pain and women's satisfaction with the experience of child birth: a systematic review. Amr J obstet Gynecol 2002;186(w):160-72.

[9]. Million Feshome, Ahmed Abdella, Solomon Kumbi, parturients' need of continuous labour support in labour ward; Ethiop J Health dev. 2007;21(1);35-39.

[10]. D Zomekhu, M.V,Maternal satisfaction with care during labour: a case study: International journal of nursing and midwifery 2011, Vol-3(3), PP 30-34.

[11]. Maria Iliadou, Supporting women in labour: Health science journal,2012, Vol-6(3): 385-391. 